\title{
Extension Methodologies for Diffusion of Dairy Innovations
}

\author{
G. Triveni ${ }^{1 *}$, G. R. K. Sharma ${ }^{1}$, Ch. Satyanarayana ${ }^{2}$, \\ K. Sarjan $\operatorname{Rao}^{3}$ and T. Raghunandhan ${ }^{4}$ \\ ${ }^{1}$ College of Veterinary Science, Tirupati, India \\ ${ }^{2}$ College of Veterinary Science, RNagar, Hyderabad, India \\ ${ }^{3}$ DSA, Sri Venkateswara Veterinary University, Tirupati, India \\ ${ }^{4}$ College of Veterinary Science, Korutla, Telangana, India \\ *Corresponding author
}

\section{A B S T R A C T}

\section{Ke ywords \\ Media Mix, Strategies, Decision support systems, Expert systems}

\section{Article Info}

Accepted:

10 July 2020

Available Online:

10 August 2020
Any information communication tool like radio, television, mobile phone, computer, network, hard ware and software, satellite system etc., can be used for framing suitable methodologies for dissemination of innovations to the livestock farmers. No single medium of communication is the best and hence a combination of different medium referred as media mix strategies were suggested through the study for diffusion of various dairy innovations. The methods suggested by the respondents were categorized into four media mix strategies to enable effective diffusion of dairy technologies among farming communities of Andhra Pradesh. Dissemination of latest scientific information on production aspects in local language through radio and television supported by group meetings and printed material ranked first followed by Access to innovations through mobile phones, mobile applications, creation of farmers what's app groups (II), Development of interactive ICT tools like expert systems, multimedia modules, information kiosks which help in capacity building to the farmers (III) and Provision of information on marketing trends, availability of feed ingredients through mobile updates / mobile telephones $(1 \mathrm{~V})$ respectively.

\section{Introduction}

The individual instruments used for information and advisory work are called media and the mode in which extension makes use of these media are called methods (Blanckenburg, 1984). Lack of proper regional specific and innovation specific methodologies may be the prime reason for meager diffusion of innovations and reaching a very limited number of farmers. No single medium of communication is the best and hence the combination of different medium of communication used to disseminate information is called as media mix. The strength of certain media can help to compensate the weakness of other media in combination. Some of the media combinations include use of radio, television (T.V), videos, mass mailings, brochures well 
supported by discussions through rural forums. Another project is use of decision support systems, information kiosks, expert systems or information dissemination through mobile phones, SMS, MMS, mobile apps, What's app groups. Any information communication tool like radio, television, mobile phone, computer, network, hard ware and software, satellite system etc., can be used for framing suitable methodologies for dissemination of innovations to the livestock farmers.

Keeping the advantages of combination of different medium of communication, few feasible extension methodologies referred as media mix strategies were suggested through the study for diffusion of various dairy innovations.

\section{Materials and Methods}

The suggestions elicited from the dairy farmers in the study area regarding the methods useful for dissemination of information were recorded during the investigation. The methods suggested were categorized into four media mix strategies to enable effective diffusion of dairy technologies among farming communities of Andhra Pradesh.

\section{Results and Discussion}

Based on the results of the investigation, needs and suggestions perceived by the dairy farmers the extension methodologies felt needy by the dairy farmers were, dissemination of latest scientific information on production aspects in local language through radio, T.V, supported by group meetings and printed material, preferably leaflets / folders (86.67\%).Better access to innovations through mobile phones, mobile applications and creation of farmers What's App groups (82.47\%).
Development of interactive ICT tools like expert systems, multimedia modules, information kiosks which help in capacity building of the farmers in the absence of expert $(78.33 \%)$. Provision of information on marketing trends, availability of feed ingredients etc., through mobile updates on mobile telephones (76.67\%). The methodologies suggested for diffusion of dairy innovations among dairy farming communities were categorized into 4 types and ranking was given to each category based on usefulness from farmer's perspective as presented in Table 1.

The results of the Table.1, depict that 'Dissemination of latest scientific information on production aspects in local language' was the methodology that ranked $1^{\text {st }}$ by 86.67 per cent of the dairy farmers. The information flow by the technical personnel and dairy experts was selective and specific and farmers were devoid of comprehensive information. Scientific advancements in dairy sector, made available in local language through radio and television in kisan programs in the evenings daily, would be of immense use for the dairy farmers. This may be followed by meetings, trainings, campaigns with supportive literature. The findings gained the support of Sethumadhavan et al., (2014) and Pradeep CA et al., (2010).

"Increased access to innovations through decision support systems" was ranked $2^{\text {nd }}$ by 82.47 per cent of the dairy farmers. The complex nature of farming, risk involved, demand for high precision, timeliness in quality decision making and marketing trends demands the farmer to elicit support from information systems. Decision support systems (DSS) analysis the data and presents it to the user so that he can make decisions more easily. However, DSS should have interactivity, personalized and adhoc reporting capability, simple web based 
deployment so that the users can utilize the same from any part of the globe. The DSS should consider the needs of the dairy farmers like formulation of balanced ration, least cost formulations, feed analysis, economic production parameters etc. These findings are line with the findings of Murugavelu (2006).

Table.1 Extension Methodologies Suggested for Adoption and Diffusion of Dairy Innovations

\begin{tabular}{|c|c|c|c|c|}
\hline S. No. & \multicolumn{1}{|c|}{ Methodology } & Frequency & Rank & \% \\
\hline $\mathbf{1 .}$ & $\begin{array}{l}\text { Dissemination of latest scientific } \\
\text { information on production aspects in local } \\
\text { language through radio and television } \\
\text { supported by group meetings and printed } \\
\text { material (leaf lets / folders) }\end{array}$ & 312 & I & 86.67 \\
\hline $\mathbf{2 .}$ & $\begin{array}{l}\text { Better access to innovations through } \\
\text { mobile phones mobile applications, } \\
\text { creation of farmers what's app groups }\end{array}$ & 297 & II & 82.47 \\
\hline $\mathbf{3 .}$ & $\begin{array}{l}\text { Development of interactive ICT tools like } \\
\text { expert systems multimedia modules, } \\
\text { information kiosks which help in capacity } \\
\text { building to the farmers }\end{array}$ & 282 & III & 78.33 \\
\hline $\mathbf{4 .}$ & $\begin{array}{l}\text { Provision of information on marketing } \\
\text { trends, availability of feed ingredients } \\
\text { through mobile updates / mobile telephones }\end{array}$ & 262 & IV & 72.67 \\
\hline
\end{tabular}

Fig.1 Extension Methodologies suggested for Adoption and Diffusion of Dairy Innovations

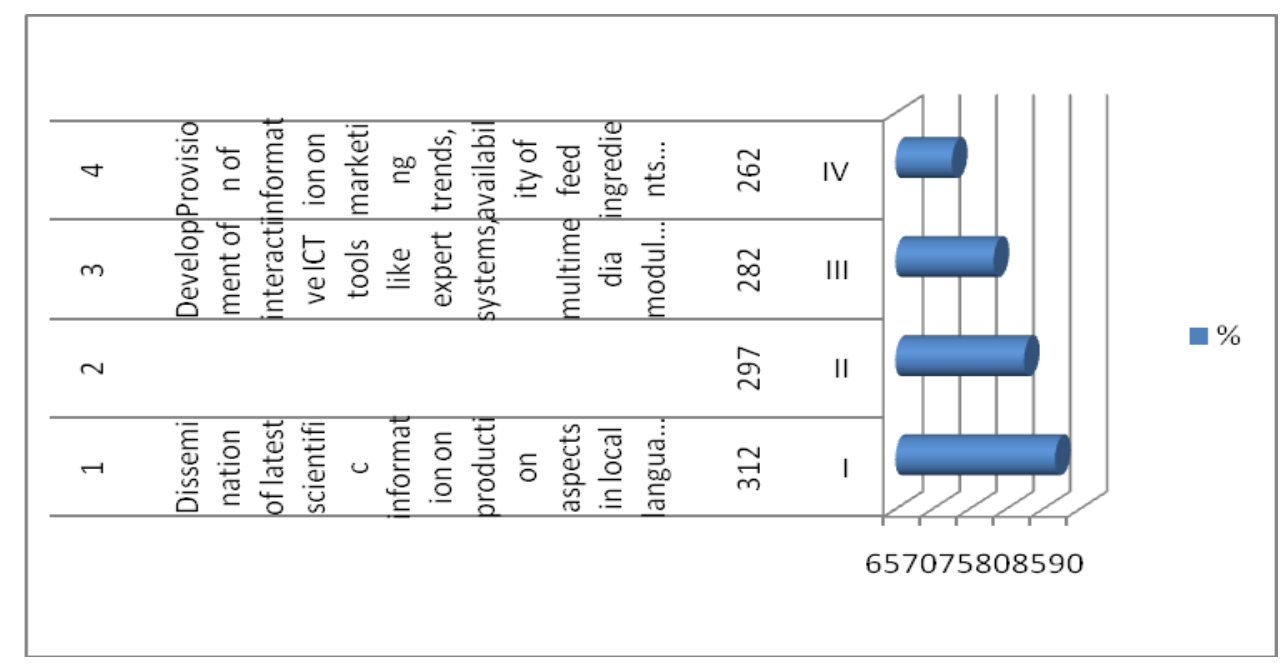

The third methodology suggested was "Development of interactive ICT tools like expert systems, multimedia modules and information kiosks for capacity building of the farmers". Very few expert systems were developed on certain domains in dairy sector and there is great scope and demand for comprehensive expert systems comprising of different independent modules. Expert systems/multimedia modules must be developed in local language which helps to aid the farmers in establishing their own 
enterprise. Expert systems / multimedia modules should be built around new technologies developed, benefits over previous practices, skill involved, profits derived etc. To disseminate technological information in a timely manner government must think about establishing information kiosk at each village to reach the last mile delivery of extension services through ICT approach which gained the support of findings of Kumar D (2005).

Provision of information on dairy innovations, market trends, feed prices etc., through mobile phones was the $4^{\text {th }}$ methodology suggested for diffusion of dairy innovations as felt necessary and useful by majority of the respondents. Mobile telephones have brought many changes in the information dissemination and made information portable. Value added information on dairy innovations, market trends, prices of feed, milk etc., may be made available through text short message service (SMS), voice SMS, MMS, mobile apps, video clips through creation of common what's app groups for farmers which is felt easy and necessary by 73 percent of the respondents. These findings are in agreement with the findings of Shenoy N.S and Benerjee P (2004).

In conclusion the present study made an effort to formulate appropriate extension methodologies to enhance the rate of adoption and diffusion of innovations among farming communities. Dissemination of latest scientific information on production aspects in local language through radio and television supported by group meetings and printed material (leaf lets / folders) are felt the need of the hour. Initiatives like establishment of information kiosk at each village to reach the last mile delivery of extension services through ICT approach, provision of information on market trends, prices of feed, milk etc., through text short message service (SMS), voice SMS, MMS, mobile apps, video clips and what's app groups effectively diffuse the technologies.

\section{References}

Blanckenburg, P.V 1984. Agricultural extension systems in some African and Asian countries. An analysis of country reports. FAO, Rome, Italy. FAO economic and social development paper. pp. 1-75.

Kumar, D 2005. Information and Communication Technology in Indian Agriculture, Dessimination of Information to Farmers. http://129.3.20.41/eps/get/papers/0503/ 0503002.pdf

Murugavelu, K 2006. Information technology solutions in agriculture development. Kisan world, 33(12): 7-8.

Pradeep, C.A and Raj Kamal P.J 2010. Availability preference and frequency of utilization of communication sources to dairy entrepreneurs. Journal of Food and Home Science, 29: (3\&4).

Sethumadhavan, T.P, Senthil Kumar R and Ram Kumar S 2014. Development of a concept model for knowledge dissemination among livestock based women self help groups in Kerala State, Kerala. The International Journal of Humanities and Social Studies, 2(\&): 200-206.

Shenoy, N.S and Banerjee P 2004. Knowledge networking in Information and Communication Technologies (ICTs) for Women in Agriculture and Rural Development. Manage Extension Review, 2: 85. 


\section{How to cite this article:}

Triveni, G., G. R. K. Sharma, Ch. Satyanarayana, K. Sarjan Rao and Raghunandhan, T. 2020. Extension Methodologies for Diffusion of Dairy Innovations. Int.J.Curr.Microbiol.App.Sci. 9(08): 1055-1059. doi: https://doi.org/10.20546/ijcmas.2020.908.115 